\title{
Prospective evaluation of artemether-lumefantrine for the treatment of non-falciparum and mixed-species malaria in Gabon
}

\author{
Ghyslain Mombo-Ngoma1 1,2,3, Christian Kleine ${ }^{1,2,4}$, Arti Basra ${ }^{1,2}$, Heike Würbel ${ }^{1,2}$, Daisy A Diop,2, Mesküre Capan ${ }^{1,2,5}$, \\ Ayola A Adegnika ${ }^{1,2,6}$, Florian Kurth ${ }^{1,2,7}$, Benjamin Mordmüller ${ }^{1,2}$, Fanny Joanny ${ }^{1,2}$, Peter G Kremsner ${ }^{1,2}$, \\ Michael Ramharter ${ }^{1,2,5^{*}}$ and Sabine Bélard ${ }^{1,2,8}$
}

\begin{abstract}
Background: The recommendation of artemisinin combination therapy (ACT) as first-line treatment for uncomplicated falciparum malaria is supported by a plethora of high quality clinical trials. However, their recommendation for the treatment of mixed-species malaria and the large-scale use for the treatment of non-falciparum malaria in endemic regions is based on anecdotal rather than systematic clinical evidence.

Methods: This study prospectively observed the efficacy of artemether-lumefantrine for the treatment of uncomplicated non-falciparum or mixed-species malaria in two routine district hospitals in the Central African country of Gabon.

Results: Forty patients suffering from uncomplicated Plasmodium malariae, Plasmodium ovale or mixed-species malaria (including Plasmodium falciparum) presenting at the hospital received artemether-lumefantrine treatment and were followed up. All evaluable patients $(n=38)$ showed an adequate clinical and parasitological response on Day 28 after oral treatment with artemether-lumefantrine $(95 \%$ confidence interval: $0.91,1)$. All adverse events were of mild to moderate intensity and completely resolved by the end of study.

Conclusions: This first systematic assessment of artemether-lumefantrine treatment for P. malariae, P. ovale and mixed-species malaria demonstrated a high cure rate of $100 \%$ and a favourable tolerability profile, and thus lends support to the practice of treating non-falciparum or mixed-species malaria, or all cases of malaria without definite species differentiation, with artemether-lumefantrine in Gabon.
\end{abstract}

Trial Registration: ClinicalTrials.gov Identifier: NCT00725777

Keywords: Malaria, Ovale, Malariae, Artemisinin-combination-therapy, Artemether-lumefantrine, Non-falciparum

\section{Background}

Effective treatment of malaria is one of the main tools to control and eventually eradicate malaria. A plethora of clinical trials demonstrating high efficacy, satisfying effectiveness, and good tolerability and safety of artemisinin combination therapy (ACT) - the current first-line treatment of falciparum malaria - has been conducted and published over the past decade [1,2]. Treatment recommendations for non-falciparum malaria have however

\footnotetext{
* Correspondence: michael.ramharter@meduniwien.ac.at

'Medical Research Unit, Albert Schweitzer Hospital, Lambaréné, Gabon

${ }^{2}$ Institute of Tropical Medicine, University of Tübingen, Tübingen, Germany

Full list of author information is available at the end of the article
}

remained virtually unchanged since the introduction of chloroquine more than five decades ago [3].

Plasmodium falciparum and to a lesser extent Plasmodium vivax have attracted more scientific interest compared to the other human plasmodial species due to their high incidence, virulence and the emergence of drug resistant isolates. Today Plasmodium ovale and Plasmodium malariae are among the most neglected tropical diseases particularly in sub-Saharan Africa. This fact is illustrated by an analysis of clinical trials on $P$. ovale and $P$. malariae malaria resulting in less than five interventional clinical trials over the past 10 years, compared to 930 reports of clinical trials for P. falciparum malaria [4]. More research activities 
are, therefore, needed to boost the development of novel and improved control tools for these plasmodial infections.

Today chloroquine remains the standard of care for P. malariae and $P$. ovale malaria due to its low cost and sustained efficacy. ACT is recommended as first-line treatment for P. falciparum malaria and for mixed plasmodial infections [3]. Despite these official recommendations, ACT is used in many areas for the treatment of all forms of malaria including non-falciparum infections. This may be explained by the fact that non-falciparum species often occur concurrently with $P$. falciparum as mixed infections in sub-Saharan Africa [5-7], and that clinicians prefer the prescription of an ACT for malaria cases due to lacking or unreliable species differentiation. Finally, chloroquine treatment is unpopular in many parts of sub-Saharan Africa due frequently experienced adverse effects, e.g. induced pruritus.

At present, artemether-lumefantrine is the most widely used ACT worldwide with 130 million treatment courses procured in 2010 [8]. Anecdotal evidence indicates that artemether-lumefantrine may be highly efficacious against P. malariae, P. ovale and mixed-species malaria, however, a prospective evaluation is still lacking. Since artemetherlumefantrine is used on a large scale for these indications in sub-Saharan Africa we assessed the efficacy of artemether-lumefantrine in patients suffering from uncomplicated malaria due to non-falciparum species or mixed malaria species infections presenting at two district hospitals in the Central African country of Gabon.

\section{Methods}

This prospective study was performed in Gabon at the Medical Research Unit of the Albert Schweitzer Hospital in Lambaréné [9] and the Regional Hospital of Fougamou. This Central African region is characterized by perennial transmission of P. falciparum [10] and co-endemicity of $P$. ovale and P. malariae [5]. Young children and pregnant women are at highest risk for malaria associated morbidity and mortality in this region [11-13]. Plasmodium falciparum isolates are highly resistant to chloroquine and sensitivity to antifolate anti-malarials has decreased [14-16], hence ACT has become the first-line treatment of malaria [17]. The study followed the principles of the Declaration of Helsinki (5th revision) and was approved by the regional ethics committee (CERIL). Written informed consent was obtained prior to inclusion in the study from adult participants or from a legal representative of children below 21 years of age, and assent was obtained where applicable.

Participants older than six months presenting with fever or with a history of fever during the previous four days and for whom malaria was confirmed by a thick blood smear were considered for inclusion. Thick and thin blood smears were performed and patients positive for $P$. ovale, $P$. malariae or a mixed infection with more than one plasmodial species (including $P$. falciparum) at a density of below $200,000 / \mu$ l blood were considered eligible for enrolment.

Patients were excluded from this study when presenting with a clinical condition requiring hospitalization, haemoglobin $<7 \mathrm{~g} / \mathrm{dl}$, history of hypersensitivity to artemether-lumefantrine, prior intake of any anti-malarial medication, or current pregnancy or breastfeeding. Demographic data, medical history, physical examination, and axillary temperature were recorded at inclusion. Blood was obtained for haemoglobin measurement (HemoCue AB, Ängelholm, Sweden), malaria diagnostics, and storage on filter papers for molecular analysis. Axillary temperature and blood films were sequentially taken twice daily (at hours $0,8,24,36,48$ and 60) during the treatment period. Follow up visits were scheduled for clinical examination, haemoglobin measurement, and malaria diagnostics on Days 7, 14 and 28 after the start of treatment.

Oral treatment with the standard six doses artemetherlumefantrine regimen $\left(\right.$ Coartem $^{\circledR}$ and Coartem Dispersible ${ }^{\circledR}$ ) was administered on three consecutive days. Artemether-lumefantrine was given as tablets or dispersible tablets under supervision with a small amount of liquid and patients were encouraged to consume simultaneously fatty food following current recommendations by the manufacturer.

Due to the well-known limitations of microscopic malaria species differentiation in routine laboratories in subSaharan Africa, PCR analysis based on the sequence of the small subunit ribosomal RNA (ssrRNA) gene and optional sequencing were performed for final plasmodial species classification. Capillary blood was collected on filter paper (Whatmann ${ }^{\circledR}$ ) for subsequent PCR analysis. DNA was extracted with a commercial extraction kit (QIAamp DNA Blood Mini Kit, Qiagen) following manufacturer instructions and stored at $-20^{\circ} \mathrm{C}$ for further analysis. Species-specific nested PCR for P. falciparum, $P$. malariae, $P$. ovale curtisi and $P$. ovale wallikeri was carried out as previously described [18-21]. In samples not showing an amplicon for further species differentiation, a fragment of caseinolytic protease $\mathrm{C}$ gene (clpc) or cytochrome $b$ gene was amplified by nested PCR [22] and subsequently sequenced on an ABI3100 Genetic Analyzer.

The primary objective was to assess the efficacy of artemether-lumefantrine for the treatment of nonfalciparum and mixed plasmodial infections. The primary efficacy endpoint was the adequate clinical and parasitological response on Day 28. Re-appearing parasitaemia was further classified by PCR genotyping as treatment failure or newly acquired infection [19] except for $P$. ovale infections where potential relapse from liver hypnozoites precludes such a distinction. Secondary endpoints included descriptive assessment of safety, tolerability, parasite clearance time (PCT) and fever clearance time (FCT). 
A sample size of 40 patients was shown to be sufficient to demonstrate a lower $90 \%$ confidence interval of adequate clinical and parasitological response of at least $90 \%$ with a power of 0.8 assuming more than $98 \%$ efficacy on day 28. The intention to treat population (ITT) was defined as primary outcome for tolerability and safety analysis and comprised of all patients included in the study. Per protocol population (PP) was defined as primary efficacy outcome and consisted of all patients having received a full course of study medication who were not prematurely withdrawn from follow up.

Data were captured on paper case record forms and transcribed to an electronic database. All data were checked manually and further statistical analysis was performed using JMP 5.0 (SAS Institute Inc., NC, USA). Descriptive statistics of baseline characteristics and outcome measures were computed.

\section{Results}

Between July 2008 and July 2010, 40 patients were included in this study. One patient decided to withdraw consent before treatment initiation and another participant was excluded from the final analysis because of reported concomitant chloroquine intake. All 39 patients completed 28 day follow up and final analysis was done for 38 patients ( 15 female participants, 39\%). The age of patients ranged from two to 50 years, with eight patients aged less than five years and 19 between five and 12 years of age. Baseline parasitaemia ranged from 31 - 100,680 trophozoites per microliter capillary blood (median $777 / \mu \mathrm{l}$ ) (Table 1). Based on microscopy thirty-two patients had

Table 1 Patient characteristics

\begin{tabular}{|c|c|c|}
\hline \multicolumn{3}{|l|}{ Study flow } \\
\hline Patients included & 40 & $100 \%$ \\
\hline Evaluable patients & 38 & $95 \%$ \\
\hline \multicolumn{3}{|l|}{ Baseline characteristics } \\
\hline Females & 15 & $39 \%$ \\
\hline Age $^{1}$ & 8 & $5-14$ \\
\hline Children $<5$ years of age & 8 & $21 \%$ \\
\hline Systolic blood pressure $(\mathrm{mmHg})^{1}$ & 100 & $90-110$ \\
\hline Heart rate $(/ \mathrm{min})^{1}$ & 88 & 68-104 \\
\hline Haemoglobin $(\mathrm{g} / \mathrm{dl})^{1}$ & 11.3 & $10.1-12.4$ \\
\hline Haemoglobin in children $<5$ years $(\mathrm{g} / \mathrm{dl})^{1}$ & 11.5 & $10.0-12.6$ \\
\hline Haemoglobin in patients $>5$ years $(\mathrm{g} / \mathrm{dl})^{1}$ & 11.3 & $10.2-12.6$ \\
\hline Asexual parasitaemia $^{1}$ & 777 & $266-3053$ \\
\hline Asexual parasitaemia in children $<5$ years ${ }^{1}$ & 480 & $278-742$ \\
\hline Asexual parasitaemia in patients $>5$ years ${ }^{1}$ & 849 & $225-6400$ \\
\hline Participants presenting with fever & 5 & $13 \%$ \\
\hline
\end{tabular}

1 median, interquartile range.

ACPR adequate clinical and parasitological response.

95\% Cl 95\% confidence intervals. mixed-species infections and 7 patients presented with a non-falciparum mono-infection.

Eight hours after initiation of anti-malarial treatment 12 (32\%) patients had cleared parasites in peripheral blood. Further 19 patients (50\%) showed parasite clearance at 24 hours and all patients $(100 \%)$ had cleared parasites within 36 hours. Median parasite clearance time was 24 hours. Median parasite clearance time was comparable in children below 5 years of age and adults (Table 2). Patients with higher parasite densities on inclusion had longer parasite clearance times. Only a minority of patients presented with fever at inclusion $(\mathrm{n}=5,13 \%)$ and all cleared fever within 36 hours after initiation of treatment. All evaluable patients had an adequate clinical and parasitological response on Day 28 and the overall cure rate was therefore 100\% (95\% CI: 91-100\%).

Tolerability and safety of the artemether-lumefantrine was assessed for all patients from inclusion to Day 28. No serious adverse event was recorded in the course of this clinical trial and eight patients experienced adverse events (diarrhoea, urinary tract infection, convulsion, vomiting, cephalgia, abdominal pain, fever, and lymphadenopathy). Five adverse events were of mild severity (urinary tract infection, vomiting, cephalgia, abdominal pain), the other three adverse events were of moderate severity, and all adverse events completely resolved by the end of follow-up. The only adverse event considered as possibly study drug related was the occurrence of one episode of vomiting on day 1 after first drug administration.

Capillary blood was obtained and further tested by PCR for molecular species differentiation. In this analysis 19 out of 39 samples were confirmed as non-falciparum or mixed species infection. In the remaining 20 samples PCR analysis demonstrated amplification of $P$. falciparum isolates only and no amplification of non-falciparum parasitespecific amplicons. Presence of $P$. malariae mono-

Table 2 Patient outcomes

\begin{tabular}{|c|c|c|}
\hline Outcome Parameters & & \\
\hline Patients with ACPR (n, 95\% Cl) & 38 & $91-100 \%$ \\
\hline Parasite clearance time (hours) ${ }^{1}$ & 24 & $8-24$ \\
\hline Parasite clearance time in children $<5$ years (hours) ${ }^{1}$ & 24 & $24-33$ \\
\hline Parasite clearance time in patients $>5$ years (hours) ${ }^{1}$ & 24 & $8-24$ \\
\hline Fever Clearance Time $\left(n=5\right.$, hours) ${ }^{1}$ & 8 & $8-30$ \\
\hline Patients experiencing any serious adverse event & 0 & $0 \%$ \\
\hline Patients experiencing any adverse event & 8 & $20 \%$ \\
\hline Haemoglobin D28 (g/dl) ${ }^{1}$ & 11.6 & $10.6-12.3$ \\
\hline Haemoglobin D28 in children $<5$ years $(\mathrm{g} / \mathrm{dl})^{1}$ & 11.1 & $10.6-12.5$ \\
\hline Haemoglobin D28 in patients $>5$ years $(\mathrm{g} / \mathrm{dl})^{1}$ & 11.7 & $10.5-12.2$ \\
\hline
\end{tabular}


infection and mixed species infection was demonstrated in one and 18 samples, respectively. Mixed infections were confirmed by PCR analysis indicating co-infection with P. falciparum and P. ovale $(\mathrm{n}=12,63 \%), P$. falciparum and $P$. malariae $(\mathrm{n}=3,16 \%)$ and concurrent occurrence of all three species in three samples $(n=3,16 \%)$. P. ovale curtisi $(\mathrm{n}=9)$ as well as $P$. ovale wallikeri $(\mathrm{n}=10)$ isolates were present in the samples, concurrent presence of $P$. ovale curtisi and P. ovale wallikeri was found in four patients.

\section{Discussion}

This is the first prospective assessment of artemetherlumefantrine in the treatment of $P$. ovale, $P$. malariae and mixed-species infection with $P$. falciparum. The results demonstrate rapid parasite and fever clearance when assessed twice daily and a reassuringly high cure rate of $100 \%$ on Day 28 . No clinical or parasitological treatment failure occurred during the 28 day follow up period. The primary hypothesis of an adequate clinical and parasitological response rate above 90\% could, therefore, be confirmed. Although - at least in theory the occurrence of recrudescent parasitaemia after Day 28 cannot be ruled out, a longer follow-up period was precluded due to the potential for relapse of $P$. ovale infections and associated problems in classification as treatment failure or reinfection in such circumstances. Anti-relapse therapy with primaquine in $P$. ovale infection is not commonly prescribed in Gabon due to the high risk for reinfection and safety concerns in G6PD deficient individuals.

A limitation of the study design may be seen in the lack of a control group. However, due to frequent occurrence of mixed infections including $P$. falciparum, a randomized controlled trial design comparing standard chloroquine treatment with artemether-lumefantrine was precluded due to concerns for patients' safety. Future randomized clinical trials evaluating different forms of ACT versus chloroquine in the treatment of $P$. malariae or $P$. ovale mono-infections would however be highly desirable. Despite recent reports of delayed parasite clearance of $P$. malariae and $P$. ovale to chloroquine the curative efficacy of this drug appears to be maintained [23]. In analogy to mixed malaria infections of $P$. falciparum with $P$. malariae and $P$. ovale in Africa, co-endemicity of $P$. vivax and P. falciparum in South East Asia requires more rigorous assessment of the use of ACT in general, and artemether-lumefantrine in particular, for the treatment of $P$. vivax malaria [24,25]. Solid evidence of the efficacy of ACT in the treatment of non-falciparum malaria is essential before removal of chloroquine from the market as a cheap over the counter drug taken for undiagnosed and undifferentiated malaria cases.

The discrepancy between microscopic and molecular species classification as observed in this study is striking but not unexpected. Firstly, microscopic determination of mixed infections is prone to misclassification due to the relative predominance of $P$. falciparum trophozoites and often low parasitaemia of the non-falciparum species. Microscopic assessment may, therefore, under- or over- estimate mixed species infections. To minimize this source of misclassification internal and external quality control systems for microscopic malaria diagnosis are present in most African malaria research institutions, but not in smaller hospitals or other primary care facilities. In this study, microscopists were under external quality assessment and an expert senior microscopist was available to decide on discrepant results. However, despite these measures a significant proportion of patients showed discrepant results in microscopy and PCR. This discrepancy is likely to be even more important in routine laboratories without the additional quality control mechanisms. This fact further underlines potential advantages of a single treatment algorithm for all plasmodial species since misclassification may lead to the prescription of inadequate and potentially ineffective anti-malarials. Molecular determination of non-falciparum and mixed species infection may also lead to misclassification. The phenomenon of low sensitivity for the detection of mixed species and non-falciparum infections by PCR was previously described and may be explained by multiple factors [26]. DNA recovery of low-level parasitaemia in mixed infections may be too low, potentially leading to an underestimation of mixed infections. Use of frozen blood samples instead of filter paper sampling may improve the yield of DNA extraction and should be compared to dried blood samples in future studies of mixed infections. Most importantly, no difference in the clinical or parasitological response was noticed for PCR confirmed and un-confirmed cases. Hence, artemether-lumefantrine is as an excellent option for the treatment of patients with non-falciparum and mixed species infection. Since the prevalence of chloroquine resistance in Gabon is almost 100\% [27], chloroquine treatment of those patients with submicroscopic P. falciparum and microscopically detected non-falciparum mixed infection $(\mathrm{n}=6(15 \%)$ in this study) is likely to fail.

This data support the current practice of using artemisinin-combination therapy for the treatment of non-falciparum and mixed plasmodium infections or indeed clinically suspected malaria without prior species diagnosis in Central Africa. Besides high efficacy, proven safety and tolerability of artemether-lumefantrine, the use of this combination may also reduce the risk of treatment failure due to misdiagnosis of plasmodial species. However, contrary to our findings, two recent reports of clinical failures of artemether-lumefantrine treatment of $P$. falciparum and $P$. malariae mixed infections challenge this assumption $[28,29]$. Whether these reports are the rare 
exception or whether late recurrence of $P$. malariae constitutes a significant problem needs further evaluation.

Non-falciparum infections and mixed plasmodial species infections constitute a common infectious disease entity in tropical regions. In the setting of this study these infections account for an estimated 5-10\% of malaria cases indicating the importance of non-falciparum and mixed species infections. With the exception of the recently conducted clinical development program of pyronaridineartesunate combination therapy for the treatment of vivax malaria [30], non-falciparum malaria has been utterly neglected in anti-malarial drug development until these days accounting for less than $1 \%$ of published anti-malarial trials [4]. The conduct of clinical trials providing more evidence on the appropriate treatment of such infections therefore seems mandatory.

\section{Conclusions}

In conclusion, this report constitutes the first prospective assessment of artemether-lumefantrine in the treatment of $P$. ovale, P. malariae, and mixed-species malaria. The demonstrated high cure rate of $100 \%$ and the proven favourable tolerability profile of artemether-lumefantrine lend support to the approach of treating non-falciparum or mixed species malaria or indeed all cases of malaria without the possibility of species differentiation with artemether-lumefantrine combination therapy in the Central African country of Gabon.

\section{Competing interests}

The authors declare that they have no competing interests.

\section{Acknowledgments}

We acknowledge all the participants for their contribution to this study.

\section{Author details \\ ${ }^{1}$ Medical Research Unit, Albert Schweitzer Hospital, Lambaréné, Gabon. ${ }^{2}$ Institute of Tropical Medicine, University of Tübingen, Tübingen, Germany. ${ }^{3}$ Département de Parasitologie-Mycologie, Faculté de Médecine, Université des Sciences de la Santé, Libreville, Gabon. ${ }^{4}$ Department of Infectious Diseases, J.W. Goethe University Hospital, Frankfurt a. Main, Germany. ${ }^{5}$ Department of Medicine I, Division of Infectious Diseases and Tropical Medicine, Medical University of Vienna, Vienna, Austria. ${ }^{6}$ Department of Parasitology, Leiden University Medical Center, Leiden, The Netherlands. ${ }^{7}$ Department of Infectious Diseases and Pulmonary Medicine Charité-Universitätsmedizin Berlin, Berlin, Germany. ${ }^{8}$ Centre for Paediatrics and Adolescent Medicine, University Medical Centre Freiburg, Freiburg, Germany.}

\footnotetext{
Authors contributions

GMN contributed to data collection, interpretation of results, production and revision of the manuscript. CK contributed to data collection, production and revision of the manuscript. $A B$ contributed to data collection, production and revision of the manuscript. HW contributed to data collection, production and revision of the manuscript. DA contributed to data collection, production and revision of the manuscript. MC contributed to data collection, production and revision of the manuscript. AAA contributed to conception and design, interpretation of data and revision of manuscript. FK contributed to conception and design, interpretation of data and revision of manuscript. BM contributed to data collection, interpretation of results, production and revision of manuscript. FJ contributed to data collection, interpretation of results, production and revision of manuscript. PGK
}

contributed to conception and design and revision of manuscript. MR contributed to conception and design, interpretation of results, production and revision of manuscript. SB contributed to conception and design, data collection, interpretation of results, production and revision of manuscript. All authors read and approved the final manuscript.

Received: 16 February 2012 Accepted: 19 April 2012

Published: 19 April 2012

\section{References}

1. Sinclair D, Zani B, Donegan S, Olliaro P, Garner P: Artemisinin-based combination therapy for treating uncomplicated malaria. Cochrane Database Syst Rev 2009, (3):CD007483. doi:10.1002/14651858.

2. Kurth F, Belard S, Adegnika AA, Gaye O, Kremsner PG, Ramharter M: Do paediatric drug formulations of artemisinin combination therapies improve the treatment of children with malaria? A systematic review and meta-analysis. Lancet Infect Dis 2010, 10:125-132.

3. WHO: Guidelines for the treatment of malaria. Secondth edition. Geneva: World Health Organization; 2010.

4. Pubmed: Accessed on September 29th 2011. For 2001-2011.

5. Borrmann S, Szlezak N, Binder RK, Missinou MA, Lell B, Kremsner PG: Evidence for the efficacy of artesunate in asymptomatic Plasmodium malariae infections. J Antimicrob Chemother 2002, 50:751-754.

6. May J, Mockenhaupt FP, Ademowo OG, Falusi AG, Olumese PE, Bienzle U, Meyer CG: High rate of mixed and subpatent malarial infections in southwest Nigeria. Am J Trop Med Hyg 1999, 61:339-343.

7. Walker-Abbey A, Djokam RR, Eno A, Leke RF, Titanji VP, Fogako J, Sama G, Thuita LH, Beardslee E, Snounou G, Zhou A, Taylor DW: Malaria in pregnant Cameroonian women: the effect of age and gravidity on submicroscopic and mixed-species infections and multiple parasite genotypes. Am J Trop Med Hyg 2005, 72:229-235.

8. WHO. Global supply of AL. Access Date June 18th 2011. [http://www.who. int/malaria/diagnosis_treatment/finance/MoU_termination_report.pdf]

9. Ramharter M, Adegnika AA, Agnandji ST, Matsiegui PB, Grobusch MP, Winkler S, Graninger W, Krishna S, Yazdanbakhsh M, Mordmuller B, Lell B, Missinou MA, Mavoungou E, Issifou S, Kremsner PG: History and perspectives of medical research at the Albert Schweitzer Hospital in Lambarene, Gabon. Wien Klin Wochenschr 2007, 119(19-20 Suppl 3):8-12.

10. Sylla EH, Kun JF, Kremsner PG: Mosquito distribution and entomological inoculation rates in three malaria-endemic areas in Gabon. Trans $R$ Soc Trop Med Hyg 2000, 94:652-656.

11. Kurth F, Belard S, Mombo-Ngoma G, Schuster K, Adegnika AA, Bouyou-Akotet MK, Kremsner PG, Ramharter M: Adolescence as risk factor for adverse pregnancy outcome in Central Africa-a cross-sectional study. PLoS One 2010, 5:e14367.

12. Ramharter M, Schuster K, Bouyou-Akotet MK, Adegnika AA, Schmits K, Mombo-Ngoma G, Agnandji ST, Nemeth J, Afene SN, Issifou S, Onnas IN, Kombila M, Kremsner PG: Malaria in pregnancy before and after the implementation of a national IPTp program in Gabon. Am J Trop Med Hyg 2007, 77:418-422.

13. Adegnika AA, Ramharter M, Agnandji ST, Ateba Ngoa U, Issifou S, Yazdanbahksh M, Kremsner PG: Epidemiology of parasitic co-infections during pregnancy in Lambarene, Gabon. Trop Med Int Health 2010, 15:1204-1209.

14. Ramharter M, Noedl H, Winkler H, Graninger W, Wernsdorfer WH, Kremsner $P G$, Winkler S: In vitro activity and interaction of clindamycin combined with dihydroartemisinin against Plasmodium falciparum. Antimicrob Agents Chemother 2003, 47:3494-3499.

15. Binder RK, Borrmann S, Adegnika AA, Missinou MA, Kremsner PG, Kun JF: Polymorphisms in the parasite genes for pfcrt and pfmdr-1 as molecular markers for chloroquine resistance in Plasmodium falciparum in Lambarene, Gabon. Parasitol Res 2002, 88:475-476.

16. Mombo-Ngoma G, Oyakhirome S, Ord R, Gabor JJ, Greutelaers KC, Profanter K, Greutelaers B, Kurth F, Lell B, Kun JF, Issifou S, Roper C, Kremsner PG, Grobusch MP: High prevalence of dhfr triple mutant and correlation with high rates of sulphadoxine-pyrimethamine treatment failures in vivo in Gabonese children. Malar J 2011, 10:123.

17. Ramharter M, Kurth FM, Belard S, Bouyou-Akotet MK, Mamfoumbi MM, Agnandji ST, Missinou MA, Adegnika AA, Issifou S, Cambon N, Heidecker JL, Kombila M, Kremsner PG: Pharmacokinetics of two paediatric artesunate 
mefloquine drug formulations in the treatment of uncomplicated falciparum malaria in Gabon. J Antimicrob Chemother 2007, 60:1091-1096.

18. Calderaro A, Piccolo G, Perandin F, Gorrini C, Peruzzi S, Zuelli C, Ricci L, Manca N, Dettori G, Chezzi C, Snounou G: Genetic polymorphisms influence Plasmodium ovale PCR detection accuracy. J Clin Microbiol 2007, 45:1624-1627.

19. Oyedeji SI, Awobode HO, Monday GC, Kendjo E, Kremsner PG, Kun JF: Comparison of PCR-based detection of Plasmodium falciparum infections based on single and multicopy genes. Malar J 2007, 6:112.

20. Singh B, Bobogare A, Cox-Singh J, Snounou G, Abdullah MS, Rahman HA: A genus- and species-specific nested polymerase chain reaction malaria detection assay for epidemiologic studies. Am J Trop Med Hyg 1999, 60:687-692.

21. Snounou G, Viriyakosol S, Zhu XP, Jarra W, Pinheiro L, Do Rosario VE, Thaithong S, Brown KN: High sensitivity of detection of human malaria parasites by the use of nested polymerase chain reaction. Mol Biochem Parasitol 1993, 61:315-320.

22. Liu W, Li Y, Learn GH, Rudicell RS, Robertson JD, Keele BF, Ndjango JB, Sanz CM, Morgan DB, Locatelli S, Gonder MK, Kranzusch PJ, Walsh PD, Delaporte E, Mpoudi-Ngole E, Georgiev AV, Muller MN, Shaw GM, Peeters M, Sharp PM, Rayner JC, Hahn BH: Origin of the human malaria parasite Plasmodium falciparum in gorillas. Nature 2010, 467:420-425.

23. Siswantoro H, Russell B, Ratcliff A, Prasetyorini B, Chalfein F, Marfurt J, Kenangalem E, Wuwung M, Piera KA, Ebsworth EP, Anstey NM, Tjitra E, Price RN: In vivo and in vitro efficacy of chloroquine against Plasmodium malariae and P. ovale in Papua, Indonesia. Antimicrob Agents Chemother 2010, 55:197-202.

24. Bassat Q: The use of artemether-lumefantrine for the treatment of uncomplicated Plasmodium vivax malaria. PLoS Negl Trop Dis 2011, 5 e1325.

25. Douglas NM, Anstey NM, Angus BJ, Nosten F, Price RN: Artemisinin combination therapy for vivax malaria. Lancet Infect Dis 2010, 10:405-416.

26. Gatti S, Gramegna M, Bisoffi Z, Raglio A, Gulletta M, Klersy C, Bruno A, Maserati R, Madama S, Scaglia M: A comparison of three diagnostic techniques for malaria: a rapid diagnostic test (NOW Malaria), PCR and microscopy. Ann Trop Med Parasitol 2007, 101:195-204.

27. Kreidenweiss A, Kremsner PG, Dietz K, Mordmuller B: In vitro activity of ferroquine (SAR97193) is independent of chloroquine resistance in Plasmodium falciparum. Am J Trop Med Hyg 2006, 75:1178-1181.

28. Smith A, Denholm J, Shortt J, Spelman D: Plasmodium species co-infection as a cause of treatment failure. Travel Med Infect Dis 2011, 9:306-309.

29. Franken G, Muller-Stover I, Holtfreter MC, Walter S, Mehlhorn H, Labisch A, Haussinger D, Richter J: Why do Plasmodium malariae infections sometimes occur in spite of previous antimalarial medication? Parasitol Res. 2012 Feb 18 Epub ahead of print.

30. Poravuth $Y$, Socheat D, Rueangweerayut $R$, Uthaisin C, Pyae Phyo A, Valecha N, Rao BH, Tjitra E, Purnama A, Borghini-Fuhrer I, Duparc S, Shin CS, Fleckenstein L: Pyronaridine-artesunate versus chloroquine in patients with acute Plasmodium vivax malaria: a randomized, double-blind, non-inferiority trial. PLoS One 2011, 6:e14501.

\section{Submit your next manuscript to BioMed Central and take full advantage of:}

- Convenient online submission

- Thorough peer review

- No space constraints or color figure charges

- Immediate publication on acceptance

- Inclusion in PubMed, CAS, Scopus and Google Scholar

- Research which is freely available for redistribution

Submit your manuscript at www.biomedcentral.com/submit
C BioMed Central 